\title{
Spatial and temporal variation of haploids and diploids in populations of four congeners of the marine alga Mazzaella
}

\author{
Carol S. Thornber ${ }^{1,2, *}$, Steven D. Gaines ${ }^{1}$ \\ ${ }^{1}$ Marine Science Institute, University of California, Santa Barbara, California 93106, USA \\ ${ }^{2}$ Present address: Center for Population Biology, University of California, One Shields Avenue, Davis, California 95616, USA
}

\begin{abstract}
Many algal species have life cycles that involve an obligate alternation of generations between nearly identical, free-living haploid and diploid individuals. The percentages of haploids to diploids, and the spatial and temporal scales of variation of these percentages, must be examined before hypotheses about the relative importance of haploid and diploid demographic processes on population dynamics can be evaluated. In this paper, we investigated the spatial and temporal dynamics of the percentage of haploid and diploid stages in 4 congeners of the marine alga Mazzaella (M. capensis, M. flaccida, M. laminarioides, and M. splendens) across large portions of their geographical ranges. For the 3 species that were sampled over multiple years (M. flaccida, M. laminarioides, $M$. splendens), the percentage of haploids varied significantly among sites. However, 2 of them ( $M$. flaccida, M. splendens) did not exhibit significant temporal (interannual) variation in the percentage of haploids. In addition, more fine-scale temporal studies on $M$. flaccida populations revealed that there were also no significant intra-annual fluctuations in the percentage of haploids, although there was significant population turnover on this timescale. This spatial variability but temporal stability of haploid-diploid ratios (for M. flaccida and M. splendens) can be used to generate, and subsequently test, hypotheses on the regulation of haploid-diploid ratios and the relative importance of haploid and diploid demographic processes on population dynamics.
\end{abstract}

KEY WORDS: Isomorphic life cycle $\cdot$ Mazzaella capensis $\cdot$ Mazzaella flaccida $\cdot$ Mazzaella laminarioides $\cdot$ Mazzaella splendens $\cdot$ Haploid $\cdot$ Diploid $\cdot$ Macroalgae

\section{INTRODUCTION}

Many species of algae have complex life cycles with multiple free-living life stages. One common example is the haploid-diploid life cycle, in which there is an obligate cycling between a haploid and a diploid phase. Diploids produce haploid spores via meiosis. These spores grow to become male and female haploid adults. Mature haploids produce gametes that subsequently fuse to complete the live cycle by producing new free-living diploids. There is substantial variation among species in the similarity of the morphology and lifespan of the free living phases. In isomorphic haploid-diploid life cycles, the independent haploid and diploid phases appear morphologically identical to each other, live in similar habitats, and are frequently lumped together in ecological studies (Gaines 1985, Kim \& De Wreede 1996). Although the phases may appear similar to an observer, they may differ ecologically (e.g. Luxoro \& Santelices 1989). The relative similarity between algal phases may have small or large effects on their populations, as has been explored in the functional form literature (Littler \& Littler 1980, Littler et al. 1987).

Several field studies of algae have examined the temporal or spatial patterns of relative abundance of the 2 phases. However, due to the difficulty of distinguishing morphologically similar haploid and diploid individu- 
als, most studies have been limited to surveying only reproductive individuals. Such selective sampling of the population can yield a biased estimate of the frequency of haploids and diploids for the entire population for a variety of reasons: males in many species may never be visually reproductive in the field and are thus never included in field surveys; seasonal variation in the timing of reproduction of haploids and diploids can generate shifts in the population structure if only reproductive individuals are sampled, even when no changes in the true frequencies of haploids and diploids occur. Ignoring such biases, studies of reproductive individuals alone have found a variety of haploid-diploid ratios in marine algae, ranging from diploid dominance (Hansen \& Doyle 1976, Allender 1977, Abbott 1980) to equal numbers of haploids and diploids (Destombe et al. 1989) to haploid dominance (Hannach \& Santelices 1985, Luxoro \& Santelices 1989).

Studies of marine algae that have included both reproductive and nonreproductive individuals are less common. They are mostly restricted to species in the Gigartinaceae (but see Engel et al. 2001), where a chemical test can distinguish haploid from diploid individuals in some species at any stage of development (Garbary \& De Wreede 1988, Shaughnessy \& De Wreede 1991). Mazzaella capensis in South Africa varied from diploid to haploid dominance at one site over a year (Bolton \& Joska 1993). M. splendens in British Columbia was also found to vary seasonally in haploid abundance (Dyck \& De Wreede 1995). Finally, geographical surveys of the M. flaccida and M. splendens species complex (treated as 1 species in that study, but see Hommersand et al. 1994 for species separation) indicated a strong geographical gradient of diploid blade dominance in Oregon and northern California, and haploid blade dominance in central and southern California during July 1982 (Dyck et al. 1985). (In that study, blades were counted, not individuals.) Since these 2 species have subsequently been shown to have different haploid-diploid ratios (Thornber 2001), this geographical pattern could instead reflect differences in the relative abundance of the 2 species.

What insights into algal population dynamics can be gained from surveys of their haploid-diploid ratios? Theory suggests that if isomorphic phases are ecologically equivalent (i.e. have equal per capita mortality and fecundity rates), haploids should constitute $59 \%$ of the population at equilibrium (Thornber 2001); for other predictions see Scrosati \& De Wreede (1999) and Richerd et al. (1993). This prediction arises because of the cost of sex; every diploid individual can produce haploid offspring, whereas only female haploids can produce diploid offspring. However, if the haploid and diploid phases are not ecologically equivalent, the percentage of haploids will deviate from this null model prediction of $59 \%$ (Thornber 2001). These differences in per capita demographic rates can have nonintuitive effects on the relative percentage of haploids. A haploid advantage relative to diploids in mortality rates (i.e. lower haploid mortality) leads to an increase in the relative abundance of haploids. By contrast, a haploid advantage in fecundity rates (i.e. higher haploid fecundity) leads to a decrease in the relative abundance of haploids, because more diploid offspring are produced.

Other mechanisms may also affect the percentage of haploids and diploids in field populations. Periodic disturbances or random events that affect haploids and diploids differently could result in a variation of haploid-diploid ratios. Moreover, since different physical and biological processes may operate along a latitudinal gradient, it is plausible that the relative abundance of the different phases may vary across a species' latitudinal range. Phases may differ in their responses to numerous factors that vary geographically (on both small and large scales), including temperature, nutrient availability, wave forces and the abundance of other interacting species (Luxoro \& Santelices 1989, Shaughnessy et al. 1996).

If the ratio within a population constantly fluctuates, determining the relative effects of haploids and diploids on the ratio may be challenging. By contrast, if a ratio remains constant across populations in one year, or across years for a particular population, studies on the effects of haploids and diploids on such a ratio will be simpler to conduct and analyze. Thus, a thorough understanding of how the percent of haploids and diploids varies spatially and temporally for a particular species is necessary before hypotheses about these demographic parameters responsible for haploid and diploid percentages in the field can be tested. In this paper, the terms haploid and diploid percentage and haploid-diploid ratio will both be used to describe the relative numerical balance between haploids and diploids in a population.

This paper focuses on 2 main questions. First, does the percentage of haploids vary between populations? Spatial variation among sites could indicate that differential demographic processes are operating at different sites, while a consistency in haploid percentage among sites could indicate that similar processes are operating across sites. Second, does the percentage of haploids vary on seasonal or yearly temporal scales? Temporal variation could indicate that processes at a site are not consistent from one year (or season) to the next, while temporal consistency could indicate that demographic processes remain constant from one year (or season) to the next.

To assess the spatial and/or temporal fluctuations in the relative abundance of haploids and diploids, we 
studied 4 congeneric species of marine algae from 3 continents - Mazzaella flaccida (Setchell et Gardener) and $M$. splendens (Bory) Fredericq from the west coast of North America, M. laminarioides (Bory) Fredericq from the west coast of South America, and M. capensis J. Ag., from the west coast of South Africa. Haploiddiploid ratios of populations of the first 3 species were tracked annually for 3 to $4 \mathrm{yr}$, and sites were located along a broad geographical scale (500 to $1200 \mathrm{~km}$, depending upon the species). Populations of $M$. capensis were sampled once to determine spatial patterns of haploid-diploid variation for this species. We also tracked populations of $M$. flaccida several times a year, to determine whether there was intra-annual variation in the percentage of haploids, since asynchronies in reproduction or other factors could potentially affect the haploid percentage characterized at a single point in time.

\section{MATERIALS AND METHODS}

Chemical test to distinguish between haploids and diploids. Four species of Mazzaella were selected for this study because they are abundant in the field, are easily identified, and because their ploidy can be determined without using reproductive structures via a simple chemical (resorcinol) test (Garbary \& De Wreede 1988, Shaughnessy \& De Wreede 1991). This test is restricted to several species in the Gigartinaceae whose haploids and diploids have different types of carrageenans in the cell walls. Ploidy level can be determined from small tissue samples, which allows for the rapid and nondestructive sampling of populations in different sites. In this study, the ploidy level of reproductive individuals was identified visually in the field from reproductive structures. An individual was classified as reproductive if at least 1 of the blades arising from its small central holdfast contained visible reproductive structures (sori for diploids, cystocarps for female haploids). (Although individuals in some algal species may overgrow each other's holdfasts, this was never observed for $M$. flaccida; no individual out of the thousands examined contained reproductive blades from both phases.) The ploidy level of nonreproductive individuals was determined chemically by taking a small tissue sample from 1 blade. This sample was later punched with a hole puncher, and the resulting disc of algal tissue was dried in a microcentrifuge tube using a small amount of silica gel. Discs of tissue were later analyzed in the lab via the resorcinol test. We modified the published protocols for this test slightly; only $1 \mathrm{ml}$ (instead of $2 \mathrm{ml}$ ) of final solution was used per sample with identical results; and samples in solutions were left in an 80 to $90^{\circ} \mathrm{C}$ water bath for at least 2 min to ensure adequate time for the reaction to occur. This test has been demonstrated to be highly accurate for all species studied here (Shaughnessy \& De Wreede 1991, Bolton \& Joska 1993, Thornber 2001). Known standards of each life-history phase were analyzed during each run of approximately 100 samples, and the standards always reacted as predicted.

Sites sampled. We surveyed the percent of haploids and diploids present at each of several exposed rocky intertidal sites, across a broad geographical range for each species. The reported range of Mazzaella flaccida is from British Columbia to northern Baja California (Abbott \& Hollenberg 1976, Gabrielson et al. 2000), although in repeated samplings from British Columbia to Los Angeles we only found it at sites from northern Oregon to Pt. Conception, California; it has not been found recently in Baja California either (Hughey 2001). The sites sampled here span most of the present range (Boiler Bay, Oregon to Vandenberg Air Force Base, California). M. splendens ranges from Alaska to northern Baja California (Abbott \& Hollenberg 1976); sites were sampled from Boiler Bay, Oregon, to Vandenberg, California. These 2 species can appear morphologically similar in the field; however, at all sites sampled except for one (Boiler Bay), there was a clear vertical separation of the 2 species in the intertidal, with $M$. flaccida higher than $M$. splendens. At Boiler Bay, the 2 species were separated by differences in blade color and marginal smoothness. M. flaccida blades are greener and have finely serrated blade margins; M. splendens blades are redder and have smooth blade margins (Abbott \& Hollenberg 1976, C. S. Thornber pers. obs.).

In Chile, Mazzaella laminarioides is found from Punta Talca to Tierra del Fuego (Hoffman \& Santelices 1997); sites were sampled from El Quisco to Pichilemu. In Africa, M. capensis is found from Namibia to Cape Agulhas, South Africa (Stegenga et al. 1997); 5 sites were sampled from Port Nolloth to Kommetjie. For clarity, sites will always be listed from north to south regardless of hemisphere. A complete list of sites sampled and surveys performed can be found in Table 1.

Spatial and temporal sampling of haploid and diploid percentages. To determine the spatial (among site) and temporal (among year) variability in the percentage of haploids and diploids in local populations, all surveys were conducted in the following manner (except as noted). For each species, at each site, plants were sampled along 2 transects. At each site, transect lines were haphazardly placed in the middle of the Mazzaella zone at least $30 \mathrm{~m}$ from each other. Along each $10 \mathrm{~m}$ transect, a small piece of tissue was removed from the plant whose holdfast was closest to the meter tape every $0.1 \mathrm{~m}$, until 100 individuals were surveyed. If the plant had reproductive tissue, we took 
a sample containing reproductive structures. The percent of haploids was subsequently calculated from each transect. Due to the sampling design, a range of plant sizes was arbitrarily sampled at each site, from very small (blade length approx $2 \mathrm{~cm}$ ) to very large (blade length over $1 \mathrm{~m}$ for $M$. flaccida and M. splendens) individuals.
Surveys of Mazzaella flaccida in California and Oregon, USA, were conducted yearly during the late summer (August/September) at 10 sites (Boiler Bay, Cape Blanco, Harris Beach, Patrick's Pt., Glass Beach, Jug Handle, Duxbury Reef, Hopkins, Piedras Blancas, Vandenberg) in 1997, 1998, and 1999, and at 7 of the sites (all except Harris Beach, Duxbury Reef, and Hopkins)

Table 1. Mazzaella capensis, M. flaccida, M. laminarioides, and M. splendens. List of species and sites sampled, and surveys performed. C: M. capensis; F: M. flaccida; L: M. laminarioides; S: M. splendens. Years sampled are abbreviated from 1997 to 2000

\begin{tabular}{|c|c|c|c|c|c|}
\hline Site name & Location & $\begin{array}{l}\text { Haploid-diploid } \\
\text { yearly } \\
\text { surveys }\end{array}$ & $\begin{array}{l}\text { Permanent plot } \\
\text { quarterly } \\
\text { surveys }\end{array}$ & $\begin{array}{l}\text { Haploid-diploid } \\
\text { bimonthly } \\
\text { surveys }\end{array}$ & $\begin{array}{c}\text { Random plot } \\
\text { bimonthly density } \\
\text { estimates }\end{array}$ \\
\hline \multicolumn{6}{|l|}{ USA } \\
\hline Cape Meares & $45.50^{\circ} \mathrm{N}, 123.95^{\circ} \mathrm{W}$ & S 97,98 & & & \\
\hline Boiler Bay & $44.83^{\circ} \mathrm{N}, 124.05^{\circ} \mathrm{W}$ & $\begin{array}{l}\text { F } 97,98,99,00 \\
\text { S } 97,98,99\end{array}$ & F 98-99 & & \\
\hline Strawberry Hill & $44.25^{\circ} \mathrm{N}, 124.10^{\circ} \mathrm{W}$ & S 97,98 & & & \\
\hline Cape Blanco & $42.83^{\circ} \mathrm{N}, 124.55^{\circ} \mathrm{W}$ & $\begin{array}{l}\text { F } 97,98,99,00 \\
\text { S } 97,98,99\end{array}$ & & F 00 & F 00 \\
\hline Harris Beach & $42.05^{\circ} \mathrm{N}, 124.55^{\circ} \mathrm{W}$ & $\begin{array}{l}\text { F } 97,98,99 \\
\text { S } 98\end{array}$ & & & \\
\hline Patrick's Pt. & $41.13^{\circ} \mathrm{N}, 124.15^{\circ} \mathrm{W}$ & $\begin{array}{l}\text { F } 97,98,99,00 \\
\text { S } 97,98,99\end{array}$ & & F 00 & F 00 \\
\hline Glass Beach & $39.45^{\circ} \mathrm{N}, 123.8^{\circ} \mathrm{W}$ & $\begin{array}{l}\text { F } 97,98,99,00 \\
\text { S } 97,98\end{array}$ & & F 00 & F 00 \\
\hline Jug Handle & $39.37^{\circ} \mathrm{N}, 123.80^{\circ} \mathrm{W}$ & F $97,98,99,00$ & & F 00 & F 00 \\
\hline Duxbury Reef & $37.88^{\circ} \mathrm{N}, 122.68^{\circ} \mathrm{W}$ & $\begin{array}{l}\text { F 97, 98, } 99 \\
\text { S 97, 98, } 99\end{array}$ & & & \\
\hline Hopkins & $36.63^{\circ} \mathrm{N}, 121.92^{\circ} \mathrm{W}$ & $\begin{array}{l}\text { F } 97,98,99 \\
\text { S } 97\end{array}$ & F 98-99 & & \\
\hline Piedras & $35.67^{\circ} \mathrm{N}, 121.28^{\circ} \mathrm{W}$ & $\begin{array}{l}\text { F } 97,98,99,00 \\
\text { S } 98,99\end{array}$ & F $97-00$ & F 00 & F 00 \\
\hline Vandenberg & $34.72^{\circ} \mathrm{N}, 120.6^{\circ} \mathrm{W}$ & $\begin{array}{l}\text { F } 97,98,99,00 \\
\text { S } 98,99\end{array}$ & F $97-00$ & F 00 & F 00 \\
\hline \multicolumn{6}{|l|}{ Chile } \\
\hline Punta Talca & $30.92^{\circ} \mathrm{S}, 71.62^{\circ} \mathrm{W}$ & L 99 & & & \\
\hline Los Moilles & $32.23^{\circ} \mathrm{S}, 71.48^{\circ} \mathrm{W}$ & L 99 & & & \\
\hline Quintay & $33.20^{\circ} \mathrm{S}, 71.63^{\circ} \mathrm{W}$ & L 99 & & & \\
\hline Laguna Verde & $33.17^{\circ} \mathrm{S}, 71.63^{\circ} \mathrm{W}$ & L 99 & & & \\
\hline El Quisco & $33.30^{\circ} \mathrm{S}, 71.62^{\circ} \mathrm{W}$ & L 99, 00 & & & \\
\hline ECIM & $33.49^{\circ} \mathrm{S}, 71.59^{\circ} \mathrm{W}$ & L 99, 00 & & & \\
\hline Las Cruces & $33.50^{\circ} \mathrm{S}, 71.59^{\circ} \mathrm{W}$ & L 99, 00 & & & \\
\hline Pelancura & $33.51^{\circ} \mathrm{S}, 71.59^{\circ} \mathrm{W}$ & L 99, 00 & & & \\
\hline Matanzas & $33.97^{\circ} \mathrm{S}, 71.82^{\circ} \mathrm{W}$ & L 99, 00 & & & \\
\hline Pichilemu & $34.43^{\circ} \mathrm{S}, 71.98^{\circ} \mathrm{W}$ & L 99, 00 & & & \\
\hline $\begin{array}{l}\text { South Africa } \\
\text { Port Nolloth }\end{array}$ & $29.25^{\circ} \mathrm{S}, 16.87^{\circ} \mathrm{E}$ & $\mathrm{C} 00$ & & & \\
\hline Groenrivier & $31.0^{\circ} \mathrm{S}, 17.5^{\circ} \mathrm{E}$ & $\mathrm{C} 00$ & & & \\
\hline Elands Bay & $32.3^{\circ} \mathrm{S}, 18.35^{\circ} \mathrm{E}$ & $\mathrm{C} 00$ & & & \\
\hline Paternoster & $32.82^{\circ} \mathrm{S}, 17.88^{\circ} \mathrm{E}$ & $\mathrm{C} 00$ & & & \\
\hline Kommetjie & $34.13^{\circ} \mathrm{S}, 18.32^{\circ} \mathrm{E}$ & $\mathrm{C} 00$ & & & \\
\hline
\end{tabular}


during 2000 (Table 1). Sites spanned approximately $1200 \mathrm{~km}$ of the coastline. During 1997 and 1998, the number of blades of each individual sampled was also recorded, to link this study more tightly to previous ones that compared frequencies of blades, rather than individuals (e.g. Dyck et al. 1985). A very tight, significant correlation $\left(\mathrm{r}^{2}=0.93, \mathrm{p}<0.0001\right)$ between the percentage of haploid individuals and haploid blades was found (10 sites each year, $\mathrm{n}=200$ individuals and 509 to 1469 blades site $\mathrm{yr}^{-1}$ ), indicating that similar results would have been found if blades had been counted instead of individuals.

Surveys of Mazzaella splendens were conducted at many of the same sites as M. flaccida during the late summer of 1997, 1998, and 1999 (Table 1). Since this species is located very low in the intertidal zone, not all sites could be sampled in all years due to fluctuating tidal heights. Thus, only those sites sampled in each of the 3 years (Boiler Bay, Cape Blanco, Patrick's Pt., Duxbury Reef) were included in analyses of spatial and temporal variability. As with M. flaccida, in 1997 and 1998 the number of blades per individual was also recorded; there was a significant correlation $\left(\mathrm{r}^{2}=0.94\right.$, $\mathrm{p}<0.0001$ ) between the haploid-diploid ratio of blades and individuals ( 6 sites in 1997, 10 sites in 1998, $\mathrm{n}=75$ to 201 individuals, 295 to 896 blades site $\mathrm{yr}^{-1}$ ).

Surveys of Mazzaella laminarioides in Chile were conducted during the austral summers of 1999 and 2000 (Table 1). Sites spanned approximately $400 \mathrm{~km}$ of coastline. During each year, samples were collected at each site every $0.05 \mathrm{~m}$ along 2 transect lines, because the sites were much smaller than those for M. flaccida or $M$. splendens. The number of blades of each individual sampled was also recorded during the 1999 surveys; there was a tight correlation $\left(r^{2}=0.85, p<0.0001\right)$ between patterns for blades and individuals (10 sites, $\mathrm{n}=195$ to 200 individuals, 613 to 1839 blades site ${ }^{-1}$ $\left.\mathrm{yr}^{-1}\right)$.

Surveys of Mazzaella capensis in South Africa were conducted at 5 sites during the austral summer of 2000 (Table 1). Sites spanned approximately $550 \mathrm{~km}$ of coastline. At 2 of the sites, Port Nolloth and Groenrivier, plant densities were low, and each individual encountered was sampled (183 and 108, respectively).

Analyses of spatial and temporal sampling of haploid and diploid percentages. To determine whether there were significant differences across space or time for each species, data on the percentage of haploids at each transect at each site were arcsine-transformed to normalize the data. In all studies in this paper, arcsinetransformed data were checked for normality and homogeneity of variances. A general linear model platform (JMP v. 4.0.4) was used to analyze haploid percentage via 2-way random factor ANOVAs among sites and years (1-way ANOVA among sites for Maz- zaella capensis). There were 2 replicates (transects) for each site during each year.

The existence of a geographical (latitudinal) gradient in haploid percentage for each species was also explored using simple linear regression techniques. For each of the 4 species, we regressed the latitude of each site with the percentage of haploids found at that site. In these analyses, sites that were repeatedly sampled over multiple years were assigned an average of the haploid percentages.

Analyses of within-site spatial distributions of haploids and diploids. Two different analyses were performed to determine whether an appropriate spatial scale of sampling was used for the haploid-diploid surveys. First, to determine whether the phases were spatially clumped at the $0.1 \mathrm{~m}$ scale $(0.05 \mathrm{~m}$ for Mazzaella laminarioides) at which individuals were sampled, the spatial order of haploids and diploids along transects was recorded during all surveys of $M$. flaccida, $M$. laminarioides, and $M$. splendens. Individual runs tests (Zar 1984) were conducted for each transect sampled at all M. flaccida and $M$. splendens sites surveyed during 1997 and 1998, and for each transect sampled at all $M$. laminarioides sites surveyed during 1999 and 2000. p-values were adjusted with the multistage procedure (Rice 1990) to account for the large number of tests performed for each species $(40,32$, and 24 , respectively).

Second, to determine whether the location (low to high vertical zonation, and/or exposed to protected from wave forces) sampled within an intertidal site affects the percentages of haploids and diploids found, additional transects of Mazzaella flaccida were conducted. If the ratios vary significantly among areas within a site, this could impact how results of amongsite variation in haploid-diploid ratios are interpreted. At both Piedras Blancas and Vandenberg, 4 replicate transects of 50 individuals each were sampled in each of the 4 zones - low exposed, low protected, high exposed, and high protected areas - from April to June 1999. Low and high areas represented the lowest and highest vertical edges of the M. flaccida distribution. Exposed and protected areas were selected from locations within each site that either received the full impact of breaking waves (exposed) or received little impact of breaking waves (protected). Each transect was $5 \mathrm{~m}$ long, with tissue samples taken from the individual with its holdfast closest to the meter tape every $0.1 \mathrm{~m}$. The percentages of haploids were first arcsinetransformed and then examined for differences among intertidal zones via 1-way ANOVAs. The 2 sites were analyzed separately.

Intra-annual patterns of Mazzaella flaccida haploids and diploids. To determine the degree of intraannual variability in haploid-diploid ratios and population density of $M$. flaccida, populations were 
followed with 3 different studies. In the first study, a tissue sample was taken to determine the ploidy level from each individual found in permanently established plots at 4 sites; these plots were sampled quarterly for 1 to 3 yr. In the second study, haploid-diploid surveys were conducted 4 times over 7 mo at 6 sites to examine shorter-term fluctuations in haploid percentage. In the third study, the density of $M$. flaccida individuals in random plots were surveyed 3 times over 6 mo at 6 sites to address shorter-term fluctuations in population size. The rationale and design of each study are discussed in more detail below.

The rate at which individuals enter (via recruitment) and leave (via death) populations is important for studies of haploid and diploid percentages. If each individual lives for several years, for example, then sampling on bimonthly or quarterly timescales to detect differences in haploid-diploid ratios would not be appropriate. Individuals of Mazzaella produce blades that arise from a small, longer-lived holdfast (Abbott \& Hollenberg 1976). Resprouting from crustal holdfasts has been shown to be common in M. splendens in Santa Cruz, California, and Friday Harbor, Washington, respectively (Hansen 1977, May 1986). It has also been noted for M. laminarioides (Hannach \& Santelices 1985). Resprouting from crusts appears to be much less common in M. flaccida populations, as described below.

We recorded the locations of individual holdfasts by triangulating from permanent reference bolts drilled into the bedrock. Seventy-six percent of the individuals ( $\mathrm{n}=$ 795) that we marked in this fashion during early summer (June 1999) permanently disappeared within 1 yr. In addition, only $13 \%$ of the individuals $(n=240)$ that disappeared in August 1999 had a new individual appear in the same location the following May; these may have been the same individuals appearing from holdfasts, or new recruits (Thornber 2001). Thus, sampling haploid-diploid ratios of populations every few months is realistic for M. flaccida, because populations undergo significant turnover of individuals on this timescale.

Intra-annual patterns of population structure: permanent plots. To determine whether Mazzaella flaccida populations fluctuated in haploid-diploid ratios on a quarterly timescale (e.g. if haploids and diploids varied in abundance among seasons), we established and maintained 5 permanent plots at each of 4 sites (Boiler Bay, Hopkins Marine Station, Piedras Blancas, and Vandenberg) within the $M$. flaccida intertidal zone (Table 1). Each $0.5 \times 0.5 \mathrm{~m}$ plot was haphazardly placed within the $M$. flaccida zone and marked with 4 stainless steel bolts. Plots at Piedras Blancas and Vandenberg were established during June of 1997 and sampled quarterly through August 2000. These 2 sites are located on the south-central California coast; to record temporal population fluctuations over a wider geographical area, we established plots at Boiler Bay (Oregon) and Hopkins (central California) during August 1998 and sampled them quarterly through August 1999. At each sampling point, at each site, the numbers of visually reproductive haploid and diploid individuals were recorded in each plot. Tissue samples from all nonreproductive individuals were collected to identify the life stage. This data allowed us to monitor both the density of individuals as well as the percentage of haploids. Recruits were not collected, since the phases cannot be distinguished visually and sampling would most likely have resulted in their death.

To determine whether Mazzaella flaccida populations fluctuate on quarterly timescales, we analyzed changes in the density of individuals and the percentage of haploids with repeated-measures ANOVAs to determine differences among times and sites. Each plot at each site was considered one replicate. All percentage data were arcsine-transformed to normalize them. These analyses were conducted for all 4 sites from August 1998 to August 1999, as well as for only Piedras Blancas and Vandenberg from September 1997 through August 2000.

Intra-annual patterns of population structure: haploid-diploid surveys. To determine whether Mazzaella flaccida haploid-diploid ratios changed on an intraannual basis, and to broaden the results from the permanent plot surveys described above, haploid-diploid surveys were conducted at 6 sites across $M$. flaccida's range during May, July, and October 2000 (Table 1). Two replicate transects were haphazardly placed, and 100 individuals each were sampled at each transect. These data on haploid percentage were combined with data collected in an identical fashion in August 2000 (see 'Spatial and temporal sampling of haploid and diploid percentages'), so that there were data on the percentage of haploids from each site for 4 sampling dates. All percentage data were arcsine-transformed to normalize them, and each survey was treated as an individual replicate. The percentage of haploids was then analyzed with a 2-way random-factor ANOVA to determine differences among months and sites.

Intra-annual patterns of population structure: random plots. To more thoroughly demonstrate the changes in population size that occur in Mazzaella flaccida populations from spring to the fall, we repeatedly surveyed 6 sites across $M$. flaccida's range during May, August, and October 2000 (Table 1). If the percentage of haploids (from haploid-diploid surveys) does not change significantly over several months, while the density of individuals does change significantly, these findings can strengthen the observation that haploid percentage is not affected by short-term (bimonthly/quarterly) fluctuations in population size. 
At each site, we haphazardly placed two $10 \mathrm{~m}$ transect lines within each Mazzaella flaccida population, and we counted the number of individuals in a $0.25 \times$ $0.25 \mathrm{~m}$ quadrat placed once every meter along the transect line. Transects were placed in different areas on each of the 3 sampling dates, so that the same location would not be repeatedly sampled. The density of individuals per plot ( $\mathrm{n}=20$ plots site $^{-1}$ ) was analyzed with a general linear model (JMP v. 4.0.4) for a 2-way random-factor ANOVA for months and sites.

\section{RESULTS}

\section{Spatial and temporal patterns of haploid percentage}

For each of the 3 species sampled over multiple years, the percentage of haploids varied significantly among sites. There was also significant temporal variation in haploid percent for 1 of the 3 species (Mazzaella laminarioides).

The percentage of haploids of Mazzaella flaccida exhibited significant variation among sites $\left(F_{6,18}=\right.$ $6.8579, \mathrm{p}=0.0007)$ but not years $\left(F_{3,18}=0.3821, \mathrm{p}=\right.$ 0.767 ) for the 7 sites sampled all 4 years (Fig. 1), with no significant interaction $\left(F_{18,28}=0.243, \mathrm{p}=0.9986\right)$. Because the percentage of haploids did not vary across years, at each site we pooled the percentage of haploids among years and conducted a 1-way ANOVA with Tukey-Kramer a posteriori tests to determine differences among sites $\left(F_{6,49}=9.788, \mathrm{p}<0.0001\right)$. Jug Handle and Patrick's Pt., the 2 highest haploid sites (85 and $84 \%$, respectively), were found to significantly differ from Glass Beach, Piedras Blancas, and Vandenberg, the 3 lowest haploid sites $(61,62$ and $68 \%)$. The other 2 sites, Boiler Bay, and Cape Blanco (75 and $74 \%$ ), were not significantly different from any of the 7 sites. This can be seen more clearly in Fig. 1A, in which the haploid percentage was averaged across years for each site. The small interannual variation in haploid percentage in the 7 sites is shown in Fig. 1B.

The percentage of haploids of Mazzaella splendens also exhibited significant variation among sites $\left(F_{3,6}=\right.$ 15.2259, $\mathrm{p}=0.0033)$ but not years $\left(F_{2,6}=4.4933, \mathrm{p}=\right.$ $0.0642)$, with no significant interaction $\left(F_{6,12}=1.1398\right.$, $\mathrm{p}=0.397$ ) for the 4 sites sampled all 3 years (Fig. 2). Other sites that were sampled during 1 or 2 of these years reflected these patterns as well; overall, the haploid percentage varied from $49.5 \%$ at Piedras Blancas (data not shown) to $84.5 \%$ at Duxbury Reef.

If there are site-specific (not species-specific) processes that influence the percentages of haploids and diploids, we would expect to find a strong relationship between the percentage of haploids of Mazzaella flaccida and M. splendens at sites. However, there was no

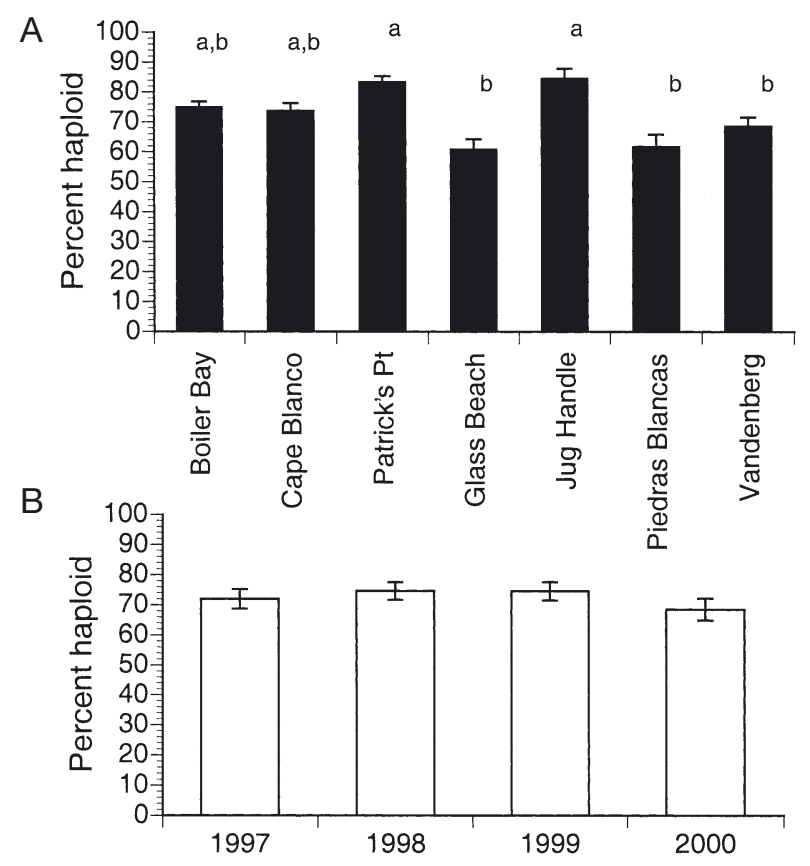

Fig. 1. Mazzaella flaccida. Percentage of haploids sampled along haphazardly placed transect lines from Boiler Bay, Oregon, to Vandenberg, California. Seven sites were sampled yearly (1997 to 2000), and 2 surveys of 100 individuals each were conducted at each site. Sites are ordered from north to south. Data are means \pm 1 SE. Percent haploids for (A) each site averaged across years (Tukey-Kramer a posteriori tests on these sites grouped them into 2 categories, a and b) and (B) each year averaged across sites

statistically significant correlation between the percentage of haploids of M. flaccida and M. splendens at individual sites during 1997, 1998, or $1999(\mathrm{p}=0.07$, 0.19 , and 0.36, respectively, $\mathrm{n}=6,8$ and 6). Although the correlation for 1997 is marginally significant, the higher $\mathrm{p}$-values for the 2 subsequent years indicate that sites were not consistently characterized by relatively low or high haploid frequencies for both species.

The percentage of haploids of Mazzaella laminarioides exhibited significant differences among sites $\left(F_{5,5}=6.3244, \mathrm{p}<0.0321\right)$ and marginally significant differences among years $\left(F_{1,5}=6.0834, \mathrm{p}=0.057\right)$, with no significant interaction $\left(F_{5,12}=1.1571, \mathrm{p}=0.3842\right)$ for the 6 sites that were sampled during 1999 and 2000 (Fig. 3). Across all sites, the average haploid percentage varied widely, from $69 \%$ at Pelancura to $90 \%$ at ECIM (Field station: Estacion Costera de Investigaciones Marinas) (Fig. 3A).

Mazzaella capensis was the one species that did not exhibit significant variation in the percentage of haploids among sites $\left(F_{4,5}=0.2750, \mathrm{p}=0.88\right)$. Sites ranged in haploid percentage from 60.2 (Elands Bay) to $66.3 \%$ (Kommetjie). 

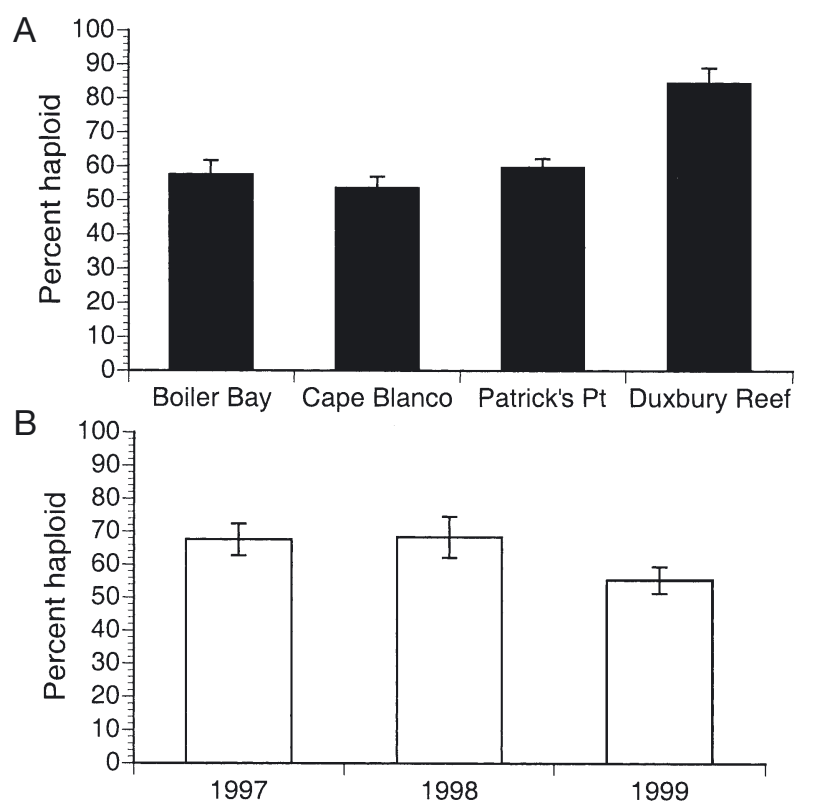

Fig. 2. Mazzaella splendens. Percentage of haploids sampled along haphazardly placed transect lines from Boiler Bay, Oregon, to Vandenberg, California. Four sites were sampled yearly (1997 to 1999), and 2 surveys of 100 individuals each were conducted at each site. Sites are ordered from north to south, and data are means \pm 1 SE. Percent haploids for (A) each site averaged across years; and (B) each year averaged across sites

\section{Latitudinal trends in the percentage of haploids}

There were no significant correlations between latitude and haploid percentage for Mazzaella flaccida, M. splendens, M. laminarioides or $M$. capensis $\left(\mathrm{r}^{2}=\right.$ $0.06,0.14,0.17,0.03$ respectively, $\mathrm{p}>0.23$ for each). In addition, significant correlations were not found when latitude and haploid percentage data were analyzed separately for each year for all species.

\section{Within-site spatial distributions of haploids and diploids}

Both analyses of smaller-scale distributions of haploids and diploids suggest that they are distributed randomly in the field within sites. The first analysis involved the linear arrangement of haploids and diploids sampled along transect lines. In nearly all cases, at the 0.1 (Mazzaella flaccida, M. splendens) and $0.05 \mathrm{~m}$ scale (M. laminarioides), runs tests revealed that haploids and diploids were not significantly clumped by phase in the field. For M. flaccida, haploids and diploids at each of all 10 sites during both 1997 and 1998 were randomly distributed ( $\mathrm{p}>0.05$ for each of 40 analyses). Results were similar for M. splendens; all 6 sites sam- pled in 1997 and 7 of 9 sites in 1998 had randomly distributed haploids and diploids ( $p>0.05$ for 30 of 32 analyses). For $M$. laminarioides, all sites sampled in 1999 and 2000 had randomly distributed haploids and diploids as well ( $p>0.05$ for each of 24 analyses).

The second analysis involved the distribution of haploids and diploids of Mazzaella flaccida at different areas (high or low, wave-exposed or protected) within a site. At Piedras Blancas, there were significant differences in haploid percentage at different locations within the intertidal (1-way ANOVA, $F_{3,12}=5.0548, \mathrm{p}=$ 0.017); Tukey Kramer HSD tests revealed that the low protected surveys had significantly higher percentages of haploids than the low exposed or high exposed surveys $(\mathrm{p}<0.05)$. The other 3 areas (high exposed, high protected, low exposed) did not significantly differ in haploid percentage. At Vandenberg, there were no significant differences in haploid percentage at the 4 locations surveyed $\left(F_{3,12}=0.8928, \mathrm{p}=0.47\right)$. This overall consistency (with the exception noted above) indicates that the intra-site variation in haploid percentage is low. All other haploid-diploid surveys discussed in this paper were conducted in the middle of M. flaccida populations (for both vertical zonation and wave exposure) to avoid such possible complications.

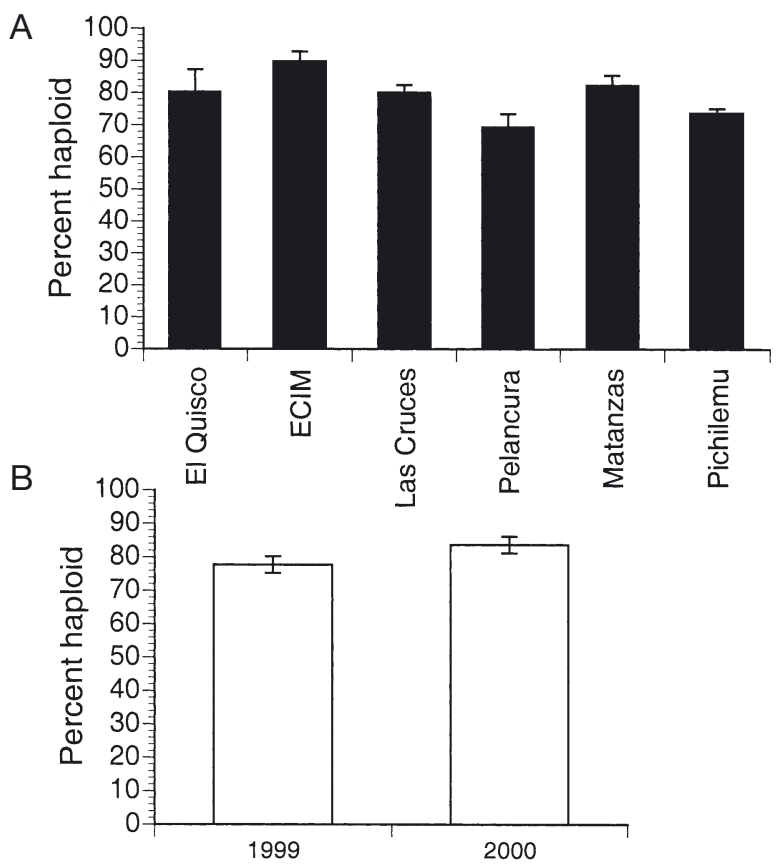

Fig. 3. Mazzaella laminarioides. Percentage of haploids sampled along haphazardly placed transect lines from El Quisco to Pichilemu, Chile. Six sites were sampled yearly (1999 and 2000 ), and 2 surveys of 100 individuals each were conducted at each site. Sites are ordered from north to south. Data are means $\pm 1 \mathrm{SE}$. Percent haploids for (A) each site averaged across years; and (B) each year averaged across sites 


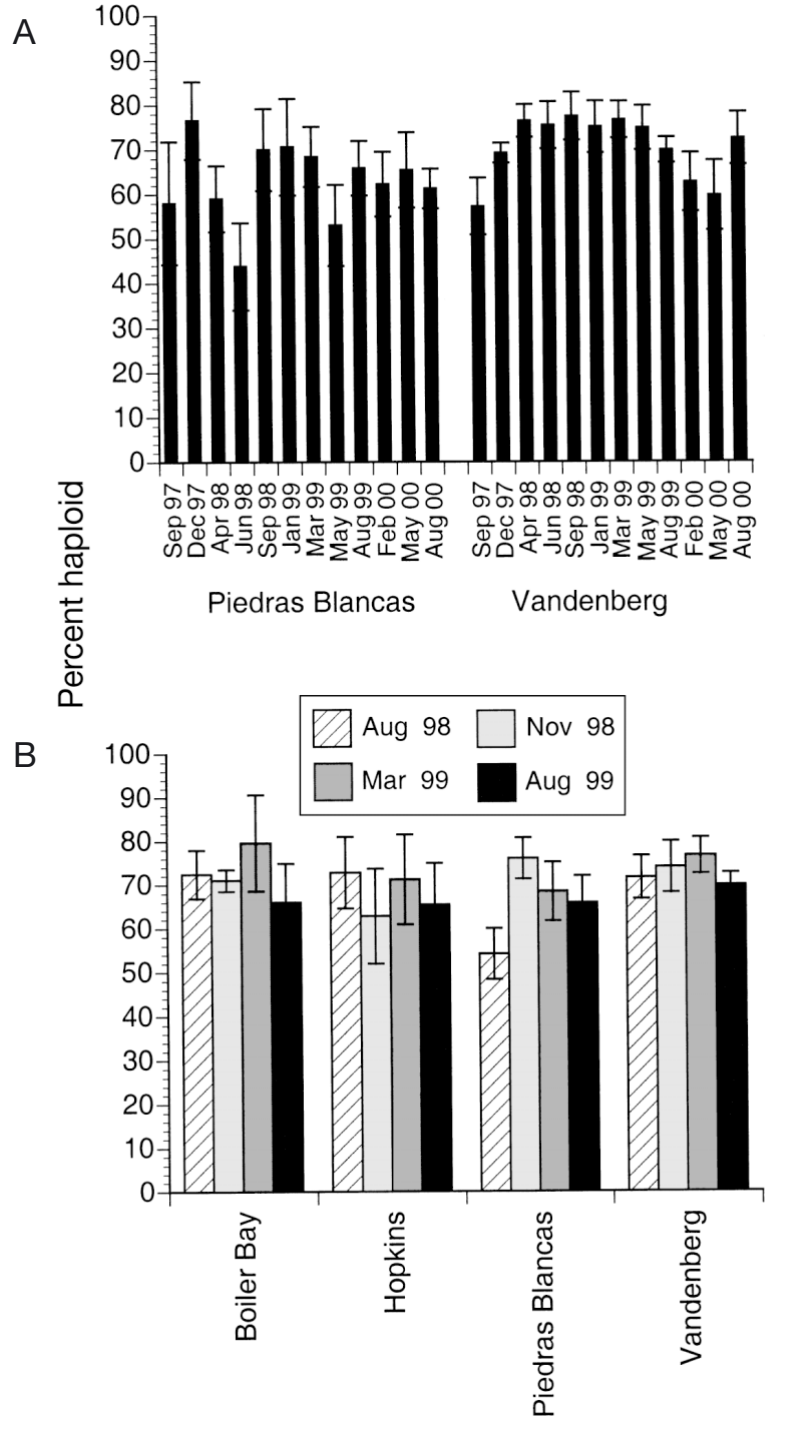

Fig. 4. Mazzaella flaccida. Percent of haploids sampled quarterly in permanent plots. Data are means $(n=36) \pm 1$ SE with 5 replicate plots $\left(0.25 \mathrm{~m}^{2}\right)$. Data from permanent plots at (A) 2 sites (September 1997 to August 2000) and (B) 4 sites (August 1998 to August 1999)

\section{Intra-annual patterns of Mazzaella flaccida haploids and diploids}

There was no significant variation among months in the percentage of haploids of Mazzaella flaccida in any of the permanent plot or haploid-diploid surveys conducted. This lack of significant variation was found in permanent plots sampled quarterly for 3 yr (Table 2, Fig. 4A) and those sampled quarterly for 1 yr (Table 2, Fig. 4B). In addition, no significant variation was found for the haploid-diploid surveys conducted 4 times over 7 mo (2-way random factor ANOVA, $F_{3,15}=1.5986, \mathrm{p}=$ $0.2315)$. Thus, the percentage of haploids found in the annual surveys is not simply an artifact of the time of year when sampling occurred, and it is evident that the relative abundance of haploids and diploids of $M$. flaccida does not change seasonally.

There were, however, significant $(p<0.02)$ temporal changes in plant density in both the permanent and random plot surveys. This was evident in the permanent plots surveyed for 1 yr (Table 3, Fig. 5A) and the random plots sampled over 6 mo (2-way random factor ANOVA, $F_{2,10}=25.51, p=0.0001$, Fig. 5B). Permanent plots sampled for $3 \mathrm{yr}$ also exhibited significant changes in plant density (data not shown). These results demonstrate that although turnover of individuals occurred throughout the study period, the consistency of the percent of haploids among times was not simply a result of the repeated sampling of the same individuals over time.

\section{DISCUSSION}

\section{Spatial and temporal patterns of haploid-diploid ratios}

The distribution of haploid and diploid individuals in local populations of species where the 2 phases are isomorphic has received increasing attention in the literature (Destombe et al. 1989, Ang \& De Wreede 1990, De Wreede \& Green 1990, Scrosati \& De Wreede 1999). Because these populations are dependent upon the persistence of both phases, populations that undergo wide oscillations between low and high haploid percentages, or populations with a very high percentage (e.g. $90 \%$ ) of either phase may be more susceptible to extinction than those that maintain a more consistent level of haploids and diploids (Thornber 2001). However, only a few studies have attempted to track populations across either spatial or temporal scales (Dyck et al. 1985, Destombe et al. 1993, Engel et al. 2001) to determine the degree to which these populations vary in their percentages of haploids and diploids. Variation in the percentage of haploids in field populations also must be known before hypotheses governing demographic (e.g. mortality, fecundity) parameters of haploids and diploids may be tested (Engel et al. 2001).

In this study, the 3 species sampled during multiple years all exhibited significant spatial variability in the percentage of haploids, and findings for one (Mazzaella laminarioides) suggested some interannual variability as well. There were also no significant interaction terms; the sites with the highest frequencies of haploids did not tend to decline while the sites with the lowest frequencies did not tend to increase. This suggests that larger-scale patterns are operating, not that sites are recovering from past displacements from a particular haploid percentage. 
Table 2. Mazzaella flaccida. Intra-annual variation in haploid percentage in permanent plots. All percentages were arcsine-transformed. A repeated-measures split-plot ANOVA, with a sphericity correction, was used to determine differences among times and sites for plots sampled repeatedly at 4 sites. Five $0.25 \mathrm{~m}^{2}$ plots were repeatedly sampled at each site. Data were analyzed for (A) 2 sites that were sampled quarterly for $3 \mathrm{yr}$ and for (B) 4 sites (including the two above) that were sampled quarterly for $1 \mathrm{yr}$

\begin{tabular}{|c|c|c|c|c|c|}
\hline & Factor & Value & $F$ & df & $\mathrm{p}$ \\
\hline \multirow[t]{5}{*}{ (A) } & Between-subjects & & & & \\
\hline & Site & 0.1177 & 0.9417 & 1,8 & 0.3603 \\
\hline & Within-subjects $^{\mathrm{a}}$ & & & & \\
\hline & Time & 0.3396 & 1.9591 & $3.7354,29.883$ & 0.1302 \\
\hline & Site $\times$ Time & 0.3395 & 2.1484 & $3.7354,29.833$ & 0.1031 \\
\hline \multirow[t]{5}{*}{ (B) } & Between-subjects & & & & \\
\hline & Site & 0.0282 & 0.1409 & 3,15 & 0.9339 \\
\hline & Within-subjects ${ }^{a}$ & & & & \\
\hline & Time & 0.5781 & 3.1186 & $1.7344,26.016$ & 0.0675 \\
\hline & Site $\times$ Time & 0.5781 & 1.1755 & $5.2032,26.016$ & 0.3483 \\
\hline
\end{tabular}

For populations of Mazzaella flaccida, significant intra-annual variation in haploid percentage was not found, in addition to the lack of significant inter-annual variation. In this study, the percent of $M$. flaccida haploids did not vary significantly within sites during quarterly sampling in Oregon and central and southern California (Fig. 4B). Longer-term quarterly sampling at 2 of these sites (Piedras, Vandenberg) from 1997 to 2000 yielded the same result (Fig. 4A). The significant changes in plant density over time (Fig. 5), and observations on the disappearance of individuals from populations (Thornber 2001) indicate that population turnover is occurring at these sites at this timescale.

Although this is the first study of the seasonal variation of Mazzaella flaccida haploids and diploids, previous studies have examined the seasonality of $M$. splendens in central California (Hansen 1976), Washington (May 1986), and Vancouver (De Wreede \& Green 1990, Dyck \& De Wreede 1995). The first 2 studies found no evidence of seasonal variation in haploid percentage, but the Vancouver studies documented a seasonal shift of haploid predominance in the summer and diploid predominance in the winter. What could explain these differences in seasonal fluctuations, both within and between species of Mazzaella? De Wreede \& Green (1990) explore this issue in depth for M. splendens. They conclude that the most likely explanation is that seasonal fluctuations in haploid percentage occur at higher latitudes (e.g. Vancouver Island, British Columbia), where there are greater shifts among seasonal weather patterns than in California or Oregon. Since we did not conduct seasonal studies of $M$. splendens, our data cannot be used to strengthen or refute this hypothesis. In addition, because all of our studies were conducted south of Vancouver (and M. flaccida's northernmost range limit is well south of Vancouver), we would not have expected to observe seasonal shifts in M. flaccida's haploid percentage, if their hypothesis is the driving mechanism. In addition, $M$. flaccida and $M$. splendens occupy different intertidal locations and may be subjected to different biotic and abiotic pressures, which may override similarities based upon their phylogenetic relationship.

We found that the percentage of haploids of Mazzaella flaccida at individual sites did not vary significantly over time (both within and among years), even though population turnover was occurring. Thus, whatever the processes are that drive the relative abundance of the 2 phases for M. flaccida, they did not vary significantly within or between years. This lack of significant temporal variability simplifies studies of population dynamics and thus makes $M$. flaccida an ideal species for experiments on the relative performance of haploids and diploids (Thornber 2001).

\section{Implications for regulation of haploid-diploid ratios}

Population models can be used to predict haploid-diploid ratios at equilibrium (Richerd et al. 1993, Scrosati \& DeWreede 1999, Thornber 2001). Observed deviations from these ratios may have several different possible explanations. For example, haploids and diploids could have different demographic rates, populations may not be at equilibrium, the model may be parameterized incorrectly, or the sampling scale (tem-

Table 3. Mazzaella flaccida. Intra-annual variation in plant density. A repeated-measures split-plot ANOVA (no sphericity correction needed) was used to determine differences among times and sites for plant density in plots sampled repeatedly at 4 sites from August 1998 to August 1999. Five $0.25 \mathrm{~m}^{2}$ plots were sampled at each site

\begin{tabular}{|lrrcc|}
\hline Factor & Value & $F$ & $\mathrm{df}$ & $\mathrm{p}$ \\
\hline Between-subjects & & & & \\
Site & 0.9263 & 4.6313 & 3,15 & 0.0175 \\
Within-subjects & & & & \\
Time & 1 & 13.6932 & 3,45 & $<0.00001$ \\
Site $\times$ Time & 1 & 2.0300 & 9,45 & 0.0577 \\
\hline
\end{tabular}




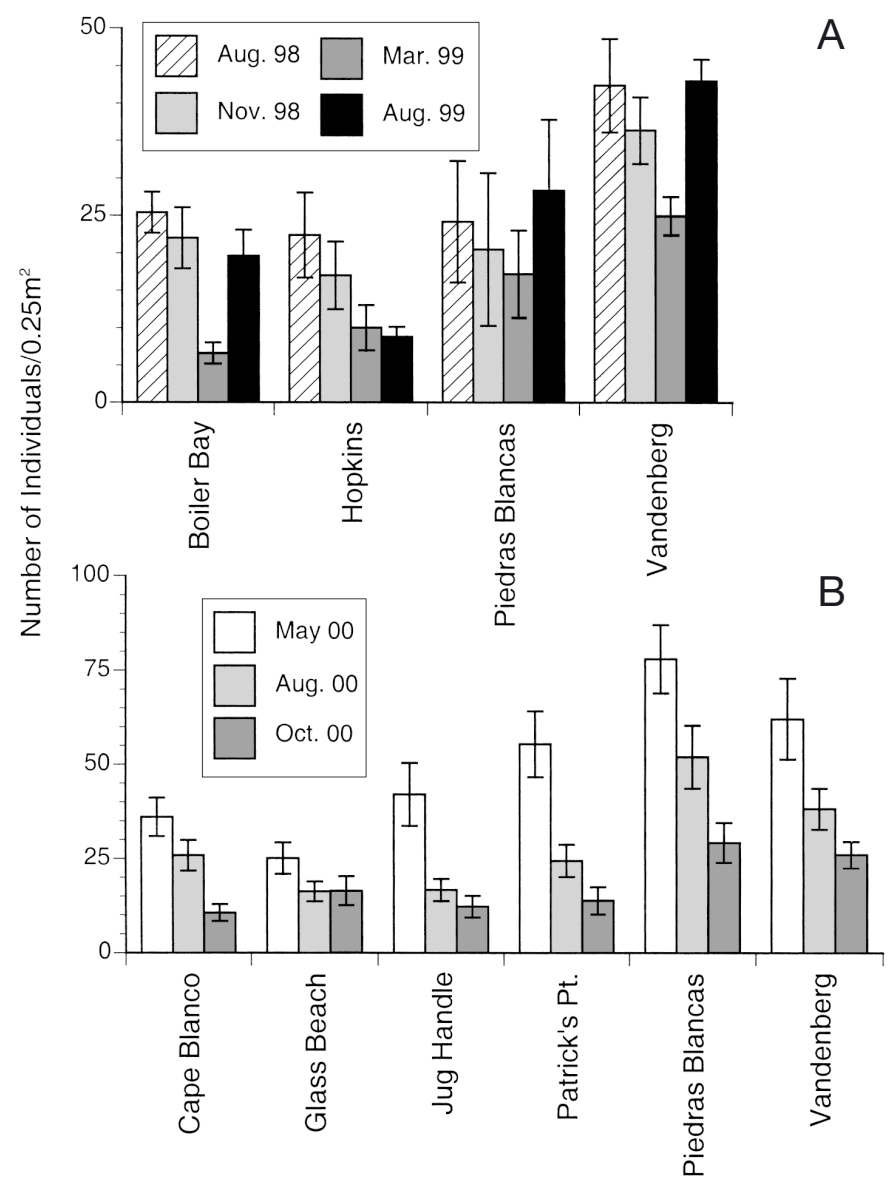

Fig. 5. Mazzaella flaccida. Density of individuals in over time (5 permanent, $0.25 \mathrm{~m}^{2}$ or 40 random, $625 \mathrm{~cm}^{2}$ plots). All data are means \pm 1 SE. (A) Permanent plots at 4 sites sampled for 1 yr from August 1998 to 1999 and (B) random plots at 6 sites (Cape Blanco, Patrick's Pt., Jug Handle, Glass Beach, Piedras Blancas, Vandenberg) sampled during May, August, and October 2000

poral/spatial) may not be appropriate for the species in question.

The consistent temporal patterns of Mazzaella flaccida and $M$. splendens (and, marginally, M. laminarioides), and the lack of a space $\times$ time interaction, indicate that it is likely that these populations are at equilibrium and are not randomly fluctuating, with respect to their percentages of haploids. The large sample sizes and repeated sampling design of this experiment make it very unlikely that these findings are due to chance.

However, there is significant spatial variation in haploid-diploid ratios for 3 of the 4 species examined here. This variability indicates that there may be differences in demographic parameters (mortality, fecundity) that vary among the sites as well. For each species, one or both of the demographic parameters (mortality, fecundity) may significantly differ between the phases. The effects of these parameters on the haploid-diploid ratio can only be determined through careful studies of algal populations, coupled with theoretical predictions of expected haploid-diploid ratios.

\section{Geographical implications}

The geographical pattern of population structure provided little insight into the causes of the observed haploid overabundance. No species showed a strong latitudinal trend in haploid frequency, unlike a previous study (Dyck et al. 1985). This may be due to a multi-year change (from that study in 1982 to ours beginning in 1997), or to differences in sampling design and species identification (see 'Materials and methods'). If isomorphic haploids and diploids differ in their responses to stresses such as temperature or wave action or ecological interactions with species that differ in abundance across these latitudinal scales (e.g. Cunningham et al. 1993, Bustamante \& Branch 1996, Kloeser et al. 1996, Travis 1996), this should be reflected in geographical trends in haploid-diploid ratios. No such patterns were found. There was substantial variation among sites, but the variation did not exhibit a consistent geographical trend.

However, haploid-diploid ratios are not the only ecological traits that may vary across geographical ranges. There may be geographical gradients in plant size, density, reproductive output, or other factors as well (Brown et al. 1995, Stone et al. 1996, West \& Zuccarello 1999). For Mazzaella flaccida, latitudinal trends in reproductive timing and plant size have been observed (C. S. Thornber pers. obs.). Northern M. flaccida populations were only reproductive during the summer and fall, while southern populations were reproductive throughout the year. In the summer, plants at northern sites were much larger than plants at southern sites (Thornber 2001).

In comparison to other marine species such as fishes and invertebrates, however, much less is known about the geographical variation of ecological traits, and their causes, in algal populations. Local variations in wave action, currents, and/or temperature can have strong effects on a species' distribution and/or an individual's size (Kloeser et al. 1996, Blanchette 1997, Graham et al. 1997, N'Yeurt \& South 1997, Tomanek \& Somero 1999). Studies of how these factors apply on biogeographical scales, however, are less common (Kopczak et al. 1991). This paper represents one of the first attempts to track populations of marine algal species across their geographical ranges. The lack of a gradient in haploid percentage across latitude, for 4 different species, is just as important a finding as if a 
strong gradient in haploid percentage had been observed. This result indicates that, for these species during this sampling period, the percentage of haploid individuals is not correlated with latitude.

Spatial variation in the percentage of haploids, however, indicates that demographic processes may vary significantly in these populations. By documenting the spatial and temporal variation in the percentage of haploids of species with multiphasic life cycles, hypotheses regarding the demographic processes of haploids and diploids, and how they might vary across a geographical range, can be tested. In this study, the lack of temporal fluctuation in haploid percentage for Mazzaella flaccida and M. splendens (and, possibly, for M. laminarioides as well) allows for subsequent testing of the relative roles of haploid and diploid demographic rates in population dynamics of these species.

Acknowledgments. S. Gaines, S. Holbrook, D. Reed, and R. Warner and 2 anonymous reviewers provided helpful comments on this manuscript. Field and lab assistance was provided by C. Berard, H. Bierlin, J. Blythe, A. Glouser, B. Kinlan, H. Patel, J. Redlin, D. Salmi, A. Simpson, and A. Torbitt in California and Oregon, and J. Rojas in Chile. Funding for this research was provided by an NSF graduate fellowship, a UC Regents fellowship, and a UC Science and Engineering research grant to C.S.T., and by the Andrew W. Mellon Foundation to S.D.G. and the David and Lucile Packard Foundation to S.D.G. and R. Warner. Support for fieldwork in Chile was provided by a Mellon Foundation grant to S. Navarrete and J. C. Castilla. This is contribution number 119 from PISCO, the Partnership for Interdisciplinary Studies of Coastal Oceans: A Long-Term Ecological Consortium, funded by the David and Lucile Packard Foundation

\section{LITERATURE CITED}

Abbott IA (1980) Seasonal population biology of some carrageenophytes and agarophytes. In: Pacific seaweed aquaculture. Proc Symp Useful Algae. NOAA, La Jolla, p 45-53

Abbott IA, Hollenberg G (1976) Marine algae of California. Stanford University Press, Stanford

Allender BM (1977) Ecological experimentation with the generations of Padina japonica Yamada (Dictyotales: Phaeophyta). J Exp Mar Biol Ecol 26:225-234

Ang PO, De Wreede RE (1990) Matrix models for algal life history stages. Mar Ecol Prog Ser 59:171-181

Blanchette CA (1997) Size and survival of intertidal plants in response to wave action: a case study with Fucus gardneri. Ecology 78:1563-1578

Bolton JJ, Joska MAP (1993) Population studies on a South African carrageenophyte: Iridaea capensis (Gigartinaceae, Rhodophyta). Hydrobiologia 260/261:191-195

Brown JH, Mehlman DW, Stevens GC (1995) Spatial variation in abundance. Ecology 76:2028-2043

Bustamante RH, Branch GM (1996) Large scale patterns and trophic structure of southern African rocky shores: the roles of geographic variation and wave exposure. J Biogeogr 23:339-351

Cunningham EM, Guiry MD, Breeman AM (1993) Environ- mental regulation of development, life history and biogeography of Helminthora stackhousei (Rhodophyta) by daylength and temperature. J Exp Mar Biol Ecol 171:1-21

Destombe C, Valero M, Vernet P, Couvet D (1989) What controls haploid-diploid ratio in the red alga, Gracilaria verrucosa? J Environ Biol 2:317-338

Destombe C, Godin J, Nocher M, Richard S, Valero M (1993) Differences in response between haploid and diploid isomorphic phases of Gracilaria verrucosa (Rhodophyta: Gigartinales) exposed to artificial environmental conditions. Hydrobiologia 260-261:131-137

De Wreede RE, Green LG (1990) Patterns of gametophyte dominance of Iridaea splendens (Rhodophyta) in Vancouver Harbor, Vancouver, British Columbia, Canada. J Appl Phycol 2:27-34

Dyck LJ, De Wreede RE (1995) Patterns of seasonal demographic change in the alternate isomorphic stages of Mazzaella splendens (Gigartinales, Rhodophyta). Phycologia 34:390-395

Dyck L, De Wreede RE, Garbary D (1985) Life history phases in Iridaea cordata (Gigartinaceae): relative abundance and distribution from British Columbia to California. Jpn J Phycol 33:225-232

Engel C, Aberg P, Gaggiotti O, Destombe C, Valero M (2001) Population dynamics and stage structure in a haploid-diploid red seaweed, Gracilaria gracilis. J Ecol 89:436-450

Gabrielson PW, Widdowson TB, Lindstrom SC, Hawkes MW, Scagel RF (2000) Keys to the benthic marine algae and seagrasses of British Columbia, southeast Alaska, Washington, and Oregon. Dept. of Botany, University of British Columbia

Gaines SD (1985) Herbivory and between-habitat diversity: the differential effectiveness of defenses in a marine plant. Ecology 66:473-485

Garbary DJ, De Wreede RE (1988) Life history phases in natural populations of Gigartinaceae (Rhodophyta): quantification using resorcinol. In: Lobban CS, Chapman DJ, Kremer BP (eds) Experimental phycology: a laboratory manual. Cambridge University Press, Cambridge, p 174-178

Graham MH, Harrold C, Lisin S, Light K, Watanabe JM, Foster MS (1997) Population dynamics of giant kelp Macrocystis pyrifera along a wave exposure gradient. Mar Ecol Prog Ser 148:269-279

Hannach G, Santelices B (1985) Ecological differences between the isomorphic reproductive phases of two species of Iridaea (Rhodophyta: Gigartinales). Mar Ecol Prog Ser 22:291-303

Hansen JE (1976) Population biology of Iridaea cordata (Rhodophyta: Gigartinaceae). MSc thesis, University of California, Santa Cruz

Hansen JE (1977) Ecology and natural history of Iridaea cordata (Gigartinales, Rhodophyta) growth. J Phycol 13:395-402

Hansen JE, Doyle WT (1976) Ecology and natural history of Iridaea cordata (Rhodophyta: Gigartinaceae): population structure. J Phycol 12:273-278

Hoffman A, Santelices B (1997) Flora Marina de Chile Central. Universidad Catolica de Chile, Santiago

Hommersand MH, Fredericq S, Freshwater DW (1994) Phylogenetic systematics of the Gigartinaceae (Gigartinales, Rhodophyta) based on sequence analysis of $r b c L$. Bot Mar 37:193-203

Hughey JR (2001) Systematics of selected Gigartinaceae (Gigartinales, Rhodophyta) with special reference to the species from Pacific North America. PhD thesis, University of North Carolina, Chapel Hill 
Kim JH, De Wreede RE (1996) Distribution and feeding preference of a high intertidal littorinid. Bot Mar 39:561-569 Kloeser H, Quartino ML, Wiencke C (1996) Distribution of macroalgae and macroalgal communities in gradients of physical conditions in Potter Cove, King George Island, Antarctica. Hydrobiologia 333:1-17

Kopczak CD, Zimmerman RC, Kremer JN (1991) Variation in nitrogen physiology and growth among geographically isolated populations of the giant kelp, Macrocystis pyrifera (Phaeophyta). J Phycol 27:149-158

Littler MM, Littler DS (1980) The evolution of thallus form and survival strategies in benthic marine macroalgae: field and laboratory tests of a functional form model. Am Nat 116:25-44

Littler MM, Littler DS, Taylor PR (1987) Functional similarity among isomorphic life-history phases of Polycavernosa debilis (Rhodophyta, Gracilariaceae). J Phycol 23:501-505

Luxoro C, Santelices B (1989) Additional evidence for ecological differences among isomorphic reproductive phases of Iridaea laminarioides (Rhodophyta: Gigartinales). J Phycol 25:206-212

May G (1986) Life history variations in a predominantly gametophytic population of Iridaea cordata (Gigartinaceae, Rhodophyta). J Phycol 22:448-455

N'Yeurt ADR, South GR (1997) Biodiversity and biogeography of benthic marine algae in the southwest Pacific, with specific reference to Rotuma and Fiji. Pac Sci 51:18-28

Rice WR (1990) A consensus combined p-value test and the family-wide significance of component tests. Biometrics 46:303-308

Richerd S, Couvet D, Valero M (1993) Evolution of the alternation of haploid and diploid phases in life cycles. II. Maintenance of the haplo-diplontic life cycle. J Evol Biol 6:263-280

Editorial responsibility: Catriona Hurd, (Contributing Editor), Dunedin, New Zealand
Scrosati R, DeWreede RE (1999) Demographic models to simulate the stable ratio between ecologically similar gametophytes and tetrasporophytes in populations of the Gigartinaceae (Rhodophyta). Phycol Res 47:153-157

Shaughnessy FJ, De Wreede RE (1991) Reliability of the resorcinol method for identifying isomorphic phases in the Gigartinaceae (Rhodophyta). J Appl Phycol 3: $121-127$

Shaughnessy FJ, DeWreede RE, Bell EC (1996) Consequences of morphology and tissue strength to blade survivorship of two closely related Rhodophyta species. Mar Ecol Prog Ser 136:257-266

Stegenga H, Bolton JJ, Anderson RJ (1997) Seaweeds of the South African West Coast. Creda Press, Cape Town

Stone L, Dayan T, Simberloff D (1996) Community-wide assembly patterns unmasked: the importance of species' differing geographical ranges. Am Nat 148:997-1015

Thornber CS (2001) The relative advantages to being haploid or diploid: modeling and field studies on three isomorphic red algal species. $\mathrm{PhD}$ thesis, University of California, Santa Barbara

Tomanek L, Somero GN (1999) Evolutionary and acclimationinduced variation in the heat-shock responses of congeneric marine snails (genus Tegula) from different thermal habitats: implications for limits of thermotolerance and biogeography. J Exp Biol 202:2925-2936

Travis J (1996) The significance of geographical variation in species interactions. Am Nat 148:S1-S8

West JA, Zuccarello GC (1999) Biogeography of sexual and asexual populations in Bostrychia moritziana (Rhodomelaceae, Rhodophyta). Phycol Res 47:115-123

Zar JH (1984) Biostatistical analysis. Prentice Hall, Englewood Cliffs, NJ

Submitted: August 21, 2002; Accepted: May 8, 2003

Proofs received from author(s): August 8, 2003 